\title{
Utilities for high throughput use of the single strand conformational polymorphism method: screening of 791 patients with familial hypercholesterolaemia for mutations in exon 3 of the low density lipoprotein receptor gene
}

Centre for Genetics of Cardiovascular Disorders,

Department of

Medicine, The Rayne Institute, University College of London Medical School, 5 University Street, London WC1E 6JJ, UK $\mathrm{R}$ Whittall

$\mathrm{V}$ Gudnason

$S$ E Humphries

I N M Day

University Clinical Biochemistry Department, Level D, South Laboratory

Block, Southampton

General Hospital,

Tremona Road,

Southampton

SO9 4XY, UK

G P Weavind

L B Day

I N M Day

Correspondence to: Dr Whittall.

Received 16 November 1994 Revised version accepted for publication 3 March 1995

R Whittall, V Gudnason, G P Weavind, L B Day, S E Humphries, I N M Day

\begin{abstract}
We have modified several aspects of the single strand conformational polymorphism (SSCP) method to increase the speed with which the technique can be used for mutation detection. The methods attain high resolution of small mobility differences using long $(30 \mathrm{~cm})$ gels and use a modified polymerase reaction to maximise detection sensitivity using a minimised quantity of ${ }^{32} \mathbf{P}$. By using custom cut "sharktooth" combs $(4.5 \mathrm{~mm}$ between teeth) as the slot formers, commercially available multichannel pipettes $(9 \mathrm{~mm}$ tip to tip) can be used to load eight or 12 samples at a time from standard microtitre plates. PCR products that have been prepared and radiolabelled using simplified protocols are loaded on to the gel, and after a precalculated time of electrophoresis another set of samples can be loaded, either with combs moved across $2.25 \mathrm{~mm}$ or onto the same gel tracks. The run conditions are calculated so that there is no overlap between the bands produced by the two loadings, thus doubling the amount of information that can be gained from one gel. A computer program has been developed to solve equations to determine suitable timings for repetitive loadings. Finally, a modification of the gel pouring system is described so that two gels can be poured between three standard glass plates, with both gels run simultaneously. Of the order of 1000 PCR reactions can be prepared and analysed in 24 man hours using five $40 \mathrm{~cm} \times 30 \mathrm{~cm}$ gel tanks. The application of these techniques is described to detect SSCPs in exon 3 of the low density lipoprotein receptor (LDLR) gene in 791 patients with familial hypercholesterolaemia (FH). Eight different SSCP patterns were seen, one of which was caused by the previously described E80K mutation, which was present in 11 patients $(1 \cdot 4 \%)$. In total, 32 patients (4\%) were identified with exon 3 mutations.
\end{abstract}

( $($ Med Genet 1995;32:509-515)

Familial hypercholesterolaemia $(\mathrm{FH})$ is a common inherited disease showing an autosomal dominant pattern of inheritance. ${ }^{1}$ It is characterised clinically by a raised concentration of low density lipoprotein (LDL) cholesterol in blood, tendon xanthomata, and an increased risk of myocardial infarction. Based on the estimated population frequency of carriers of $1 / 500$, there are more than $110000 \mathrm{FH}$ heterozygotes in the UK, of whom an estimated maximum of $80 \%$ and probably fewer than 30 to $50 \%$ are even known to have hypercholesterolaemia: fewer than $0 \cdot 1 \%$ have been confirmed at the genetic level to carry a gene for familial hypercholesterolaemia. The hyperlipidaemia and arterial lesions of these patients are responsive to treatment by diet and drugs, ${ }^{23}$ and such treatment is likely to reduce subsequent morbidity and mortality. Although management is based on the phenotype, counselling and future genetic tracing programmes will be helped by knowledge of the genotype so that definitive genetic tests can be offered. Genetic characterisation would thus be helpful both for research and in the longer term as a diagnostic tool.

$\mathrm{FH}$ commonly results from a genetic defect in the low density lipoprotein (LDL) receptor which controls the uptake of plasma LDL, and worldwide more than 140 different mutations of the LDLR gene have been characterised at the DNA level. ${ }^{4}$ Within a geographically or culturally isolated population, or where a large proportion of people are related by descent because of migration, there may be a single mutation causing $\mathrm{FH}$ in many of the patients. ${ }^{5-7}$ In the UK, where there is a very heterogeneous population, it is unlikely that any mutations will be present at a high frequency in $\mathrm{FH}$ patients. Our findings to date in a sample of $200 \mathrm{FH}$ patients from London are that $5 \%$ of patients have a gross rearrangement, ${ }^{89}$ while in a further $18 \%$ a small deletion or a single base mutation has been detected in exon 3,4 , or $14 .{ }^{10-12}$ Thus either many further mutations must be found, or a different strategy must be developed, if DNA methods are ever to become a useful adjunct to classical screening methods.

Several methods have been published which allow rapid comparison of the sequence of specific fragments of DNA amplified in vitro by the polymerase chain reaction (PCR) from different subjects. These include ${ }^{13}$ the chemical cleavage of mismatched bases and the use of 
denaturing gradient gel electrophoresis, both of which are slow and technically demanding, but which appear to detect all possible mutations. A third method is the single strand conformational polymorphism (SSCP) technique, which is based on the fact that single base changes result in conformational changes in single stranded DNA allowed to fold under non-denaturing conditions, which can be detected as a different pattern of migration on a polyacrylamide gel. ${ }^{14}$ DNA fragments are usually labelled by inclusion of ${ }^{32} \mathbf{P}$ dCTP in the amplification mixture and subsequent detection by autoradiography. This method has been more widely used than the other two, in part because it is rapid and does not use toxic chemicals or require a hybridisation step. The ability to detect differences in the migration pattern is greatest in fragments under $300-400 \mathrm{bp}$. Some studies have reported that the method does not detect all single base changes, ${ }^{15}$ and sensitivity to polymorphism can sometimes be improved for particular PCR products by a change of conditions. Our experience and that reported by others suggests that the method detects $80 \%$ to $90 \%$ of all single base changes, ${ }^{2216}$ but this is probably dependent on the sequence under study and the analytical conditions used. This method has been used successfully to detect six different mutations in the $3^{\prime}$ half of exon 4 of the LDLR gene. ${ }^{17}$ All of these give a pattern of fragments distinguishable from that seen with the normal DNA. We report here a number of modifications of standard SSCP protocols, which will improve the throughput of the technique by an order of magnitude, enabling a more comprehensive approach to the study of the molecular genetics of $\mathrm{FH}$ in hundreds of patients, or of any other disorder amenable to study by SSCP.

\section{Materials and methods PATIENTS}

A total of 791 patient samples were included in this study. Many patients or samples have been the subject of earlier clinical studies or studies of exon $4,{ }^{911} 17$ including 200 from London lipid clinics, and a variety from other centres in the UK. A further 150 from Southampton and South West Hampshire District (L B Day, I N M Day, unpublished data), and a wide range of samples sent in by other clinicians were included in this development of a practicable high throughput system for molecular genetic study of FH. All patients fulfilled clinical diagnostic criteria for "definite", "probable", or "possible" FH, and with approximately 20 exceptions are believed not to be first or second degree relatives of each other.

ISOLATION OF DNA

Genomic DNA was isolated from frozen whole blood, using serial steps of cellular lysis with a sucrose buffer, nuclear lysis including sodium dodecyl sulphate and overnight protein digestion by proteinase $\mathrm{K}$, salt precipitation of residual debris, and ethanol precipitation of DNA, as previously described. ${ }^{18}$

\section{Improved protocols for high throughput PCR and SSCP}

PCR

Exon 3 was amplified by PCR using primers flanking exon 3 . The primers were 25 bases in length. The sequence of the $5^{\prime}$ primer is 5'-TGACACTTCAATCCTGTCTCTTCTG and for the $3^{\prime}$ oligonucleotide 5'-ATAGCAAAGGCAGGGCCACACTTAC, to give a product of $172 \mathrm{bp} .^{4}$ Oligonucleotides were obtained from Genosys, USA. The amplifications were performed in an automated thermal cycler (Hybaid Omnigene) using Thermus Aquaticus (Taq) DNA polymerase (Gibco BRL, Paisley, UK) in a total volume of $20 \mu \mathrm{l}$ and overlaid with $20 \mu \mathrm{l}$ paraffin oil, using the PCR cycling conditions $96^{\circ} /$ five minutes, $68 \%$ five minutes for one cycle, $68 \%$ five minutes for 35 cycles, and $68^{\circ} /$ five minutes for one cycle. ${ }^{4}$

\section{PCR SETUP}

Microtitre arrays of dried template DNA

DNA samples were diluted to a concentration of approximately $10 \mathrm{ng} / \mu \mathrm{l}$ in $0.5 \mathrm{ml}$ in 96 well arrays, the master plate. Of this, $2.5 \mu \mathrm{l}$ was then transferred to 96 well microtitre plates (Hybaid Omnigene microtitre plates for PCR) using an eight channel multipipette. Many copies of this plate can be made, left to dry overnight, and stored at room temperature for future use.

\section{Minimisation of ${ }^{32} \mathrm{P}$ usage}

For reasons discussed below, we elected to use ${ }^{32} \mathrm{P}$ for detection of bands on SSCP gels. To minimise use of radioisotope, a modified PCR polymerase mix containing one tenth the usual concentration of dCTP was used $(0.2 \mathrm{mmol} / 1$ dATP etc, $0.02 \mathrm{mmol} / 1 \mathrm{dCTP}$ ), in conjunction with a ten-fold reduction (from 0.3 to $0.03 \mu \mathrm{Ci}$ / PCR) in necessary concentration of $[\alpha-$ $\left.{ }^{32} \mathrm{P}\right] \mathrm{dCTP}$ compared with earlier protocols. ${ }^{1419}$ The complete polymerase mix including oligonucleotides $\quad(0.8 \mathrm{pmol} / \mathrm{PCR}), \quad \mathrm{Taq}$ polymerase $(0 \cdot 2 \mathrm{U} / \mathrm{PCR})$, deoxynucleotides $(0.2 \mathrm{mmol} / 1 \mathrm{dATP}$ etc, $0.02 \mathrm{mmol} / 1 \mathrm{dCTP})$, buffer $(10 \mathrm{mmol} / 1$ Tris $\mathrm{pH} 8 \cdot 5,50 \mathrm{mmol} / 1 \mathrm{KCl}$, $0.0015 \mathrm{w} / \mathrm{v}$ gelatin), w1 $(0.05 \% \mathrm{w} / \mathrm{v})$, and $\mathrm{ra}-$ dioisotope $\left(0.03 \mu \mathrm{Ci}\left[\alpha{ }^{32} \mathrm{P}\right] \mathrm{dCTP} / \mathrm{PCR}\right)$ was premixed for distribution into wells of plates containing dried DNA templates.

SSCP

PCR product $(2 \mu \mathrm{l})$ was added to $12 \mu \mathrm{l}$ of a $7: 5$ ratio mix of formamide dye $\operatorname{mix}(95 \%$ formamide, $10 \mathrm{mmol} / \mathrm{l}$ EDTA, $0.025 \%$ bromophenol blue, $0.025 \%$ xylene cyanol FF) and a solution of $0 \cdot 1 \%(\mathrm{w} / \mathrm{v})$ sodium dodecyl sulphate (SDS) containing $10 \mathrm{mmol} / 1 \mathrm{EDTA}$. The PCR DNA was denatured at $95^{\circ} \mathrm{C}$ for five minutes and chilled immediately on wet ice; $7 \cdot 5 \mu \mathrm{l}$ samples were loaded on to a $7 \cdot 5 \%$ polyacrylamide non-denaturing gel (ratio of acrylamide to bisacrylamide of 49:1) in $1 \times \mathrm{TBE}$ buffer with $5 \%$ glycerol, $10 \mathrm{mmol} / 1$ EDTA. Gels were $40 \mathrm{~cm} \times 30 \mathrm{~cm} \times 0.4 \mathrm{~mm}$. Electro- 
phoresis was conducted at a constant voltage of $200 \mathrm{~V}$ overnight at room temperature (usually $21-25^{\circ} \mathrm{C}$ ) until the xylene cyanole had migrated $20 \mathrm{~cm}$. The gels were then transferred to Whatman $3 \mathrm{~mm}$ chromatographic paper, dried, and exposed to Hyperfilm MP (Amersham, UK) for one to four days at $-70^{\circ} \mathrm{C}$ with one intensifying screen before film development.

\section{SSCP SETUP}

Double gels

Two gels are poured between one large glass sequencing plate $(33 \times 42 \mathrm{~cm})$ and two smaller plates $(33 \times 39 \mathrm{~cm})$, so that two gels can be subjected to electrophoresis simultaneously on one apparatus. Three plates are defined: "lowest", which is the large plate and the outermost one when the arrangement is clamped to the vertical electrophoresis apparatus, "middle", and "uppermost". The terms refer to the plates as arranged horizontally on a levelling table for gel pouring. Before gel pouring, the four glass faces which will contact gel are silanised with Repelcote (BDH product number 63216 4J, BDH, Poole, UK), $2 \mathrm{ml}$ spread evenly with the edge of another glass plate. The plates are arranged with their sides aligned, with a pair of $0.4 \mathrm{~mm} \times 10 \mathrm{~mm} \times 400 \mathrm{~mm}$ spacers supporting the sides of both the middle and uppermost glass plates. The edge of the middle plate which will contact the bottom gel tank is arranged to be recessed $5 \mathrm{~mm}$ relative to the other plates. This leaves a $5 \mathrm{~mm}$ "platform" at the top, which better facilitates the insertion of the comb for the upper gel. The three plates are clamped at the sides with bulldog clips. The bottom gel (on the large plate) is poured first (by injection between the plates using a large syringe, with firm tapping to avoid the formation of bubbles during pouring), the comb inserted, and the gel left to set for 30 to 60 minutes. The second gel is then prepared identically. The gels can be stored for several days with TBE saturated tissues and clingfilm covering the ends. Care must be taken when clamping the gels to the apparatus to ensure that no air bubbles are trapped in the recess between the outermost and innermost plates in the bottom tank.

\section{Double loading gels}

After first loading the gel, the samples were electrophoresed at $400 \mathrm{~V}$ until the bromophenol blue had run 2.5 to $3 \mathrm{~cm}$, at which point the electrophoresis was stopped and a second set of SSSP samples was loaded in the same way as the first samples. Before loading the second time, the sharktooth comb was removed and repositioned half a well across from its original position. This enables the first and second loading bands to be distinguished more easily.

The first and second loading single and double strands need to be non-overlapping if the gel is to be informative. The calculation of the timing of the second loading is possible if the relative mobilities of the two single strands, one double strand, and marker dyes are already known for the set of conditions to be used.
These mobilities were determined in a previous experiment with single loading. In order that repetitive loading can be applied both to the same and different exons, we have prepared a computer simulation which enables the solution of equations relating relative mobilities, for boundary conditions including timing of loading, range of migration distance desired, and time delays between loadings (available from G P Weavind, 73064,3063@compuserve.com by email request). Double loading the gel means that a whole 96 well microtitre array of samples may be analysed on one gel.

\section{Sharktooth comb}

Sharktooth combs were custom cut with $4.5 \mathrm{~mm}$ spacing tooth to tooth to enable the use of a multichannel pipette compatible with microtitre plates ( $9 \mathrm{~mm}$ well to well spacing) for loading the SSCP gels. This results in every second well being loaded with a multichannel pipette so that two adjacent columns or rows of a microtitre plate are interleaved when loading.

\section{SCREENING BY ALLELE SPECIFIC}

OLIGONUCLEOTIDES FOR THE E80K MUTATION IN EXON 3

PCR of exon 3 was carried out as for SSCP of exon 3 but without dCTP modification and radioisotopic incorporation as described above. The PCR products were checked by electrophoresis on $7.5 \%$ polyacrylamide. Aliquots $(5 \mu \mathrm{l})$ of the PCR product were mixed with an equal volume $(5 \mu \mathrm{l})$ of a denaturing solution ( $2 \mathrm{~mol} / 1 \mathrm{NaCl} / 1 \mathrm{~mol} / 1 \mathrm{NaOH}$ ) in 96 well microtitre array format and incubated at room temperature for 15 minutes. Duplicate nylon membranes (Hybond $\mathrm{N}+$, Amersham International) were spotted with $4 \mu \mathrm{l}$ aliquots of denatured product using an eight channel pipette to give duplicate filters in grids representing the original 96 well array. Then 30 pmol of the allele specific oligonucleotides (ASOs), (FH45 (Glu) 5' TCAGACGAGCAA and FH46 (Lys) 5' TCAGACAAGCAA) were end labelled and purified using Sephadex G25 spun columns. The filters were prehybridised and hybridised in $5 \times$ SSC, $5 \times$ Denhardt's solution, $0.1 \%$ SDS at $20^{\circ} \mathrm{C}$ for 30 minutes and 90 minutes respectively. After prehybridisation in excess buffer $\left(0.1 \mathrm{ml} / \mathrm{cm}^{2}\right)$, the prehybridisation solution was changed for fresh buffer $\left(0.02 \mathrm{ml} / \mathrm{cm}^{2}\right)$ containing labelled probe. For the hybridisation $0.25 \times 10^{6} \mathrm{cpm}$ of ASO was added per $\mathrm{ml}$ of hybridisation buffer. The filters were washed for 15 minutes three times in $2 \times \mathrm{SSC} / 0 \cdot 1 \% \mathrm{SDS}$ at room temperature and then exposed to Amersham $\mathrm{Hy}$ perfilm MP for two days.

\section{Results}

We have tried a variety of labour saving approaches to achieve throughput sufficient to undertake molecular genetic studies of the LDLR gene (and other genes) in hundreds of subjects and families with a clinical diagnosis of familial hypercholesterolaemia. Several of 
Table 1 Utilities for improvement of throughput for SSCP

\begin{tabular}{|c|c|c|c|c|}
\hline Modification & Improvements & Space saving & Staff time saving & Cost saving \\
\hline \multirow{4}{*}{$\begin{array}{l}96 \text { well arrays } \\
\text { DNA templates dried pre- } \\
\text { PCR in } 96 \text { well PCR } \\
\text { plates }\end{array}$} & \multirow{4}{*}{$\begin{array}{l}\text { (1) Pre-PCR template } \\
\text { replicas readily prepared } \\
\text { (2) Minimal recording of } \\
\text { location of samples } \\
\text { (1) Easy to set up PCR, } \\
\text { only have to add } \\
\text { reaction mix. No sample } \\
\text { volume to take into } \\
\text { account } \\
\text { (2) Can be stored at } \\
\text { room temperature, no } \\
\text { requirement for fridge or } \\
\text { freezer } \\
\text { (3) No labelling of tubes }\end{array}$} & & 10 -fold & \\
\hline & & & $\begin{array}{l}\text { Estimated to save } 2 \\
\text { hours per } 100 \text { samples }\end{array}$ & \\
\hline & & & & \\
\hline & & $\begin{array}{l}\text { 4-fold compared with } \\
\text { same number of samples } \\
\text { in } 1 \mathrm{ml} \text { tubes in standard } \\
\text { box }\end{array}$ & See above & \\
\hline $\begin{array}{l}\text { Double gels (two gels } \\
\text { between three glass plates) }\end{array}$ & $\begin{array}{l}\text { Reduces number of } \\
\text { apparatus needed }\end{array}$ & 2 -fold & See douve & 2-fold \\
\hline Repeat loading of gels & $\begin{array}{l}\text { (1) Makes maximum use } \\
\text { of gels and apparatus }\end{array}$ & 2-fold & & 2 -fold \\
\hline $\begin{array}{l}4.5 \mathrm{~mm} \text { pitch sharktooth } \\
\text { combs }\end{array}$ & $\begin{array}{l}\text { (2) Improves throughput } \\
\text { (1) Improves throughput } \\
\text { of samples through } \\
\text { compatibility with } \\
\text { multichannel pipettes }\end{array}$ & & $\begin{array}{l}2 \text {-fold } \\
8 \text { - or } 12 \text {-fold }\end{array}$ & \\
\hline $\begin{array}{l}10 \text {-fold reduction of } \\
\text { unlabelled dCTP and } \\
{\left[\alpha{ }^{32} \mathrm{P}\right] \mathrm{dCTP} \text { in PCR }} \\
\text { reaction }\end{array}$ & $\begin{array}{l}\text { (1) Reduces exposure of } \\
\text { staff } 10 \text {-fold } \\
\text { (2) Reduces cost }\end{array}$ & & & 10-fold \\
\hline
\end{tabular}

these have proven to be of high utility (table 1) and in combination will increase productivity for such studies by an order of magnitude. The autoradiograph of an SSCP gel loaded by repetitive loading with two sets of samples is shown in fig 1; SSCP variants are present in both first and second loadings, and the single and double strands of both loadings can be clearly distinguished. Thirty-two SSCP variants were identified among 791 patients with a PCR failure rate of $5 \%$. These patterns were confirmed by repeat analysis from the original DNA preparations and the results of this analysis are shown in fig 2. A patient with a mutation described previously in exon 3 of the LDLR gene, E80K, was included in the current study. Although it appears that there is at least one other variation in exon 3 displaying a similar SSCP profile to this patient, we tentatively identified several other possible patients with

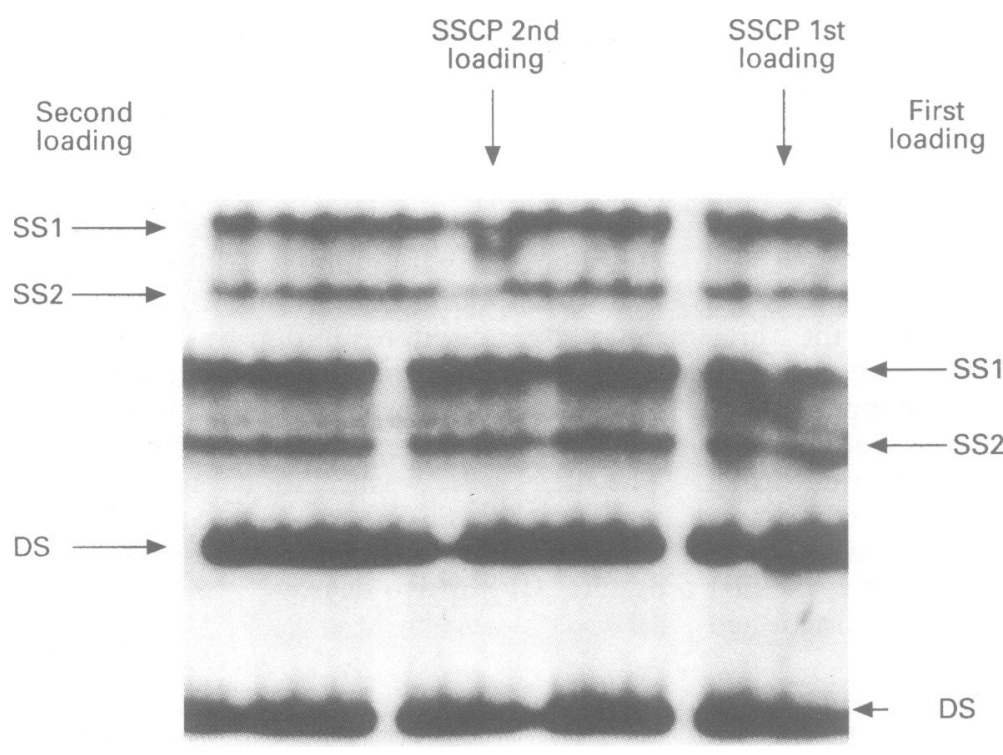

Figure 1 Autoradiograph of a double loaded SSCP gel (see Methods). The single and double strands of the first and second loadings are designated respectively on the right and left, SS1, SS2, and DS, the double strands having migrated approximately $30 \mathrm{~cm}$ and the single strands approximately $20 \mathrm{~cm}$ in the gel. SSCP variants are apparent in one sample from the first loading and in one from the second loading, as indicated. the same mutation. To confirm this, DNA from all people with an SSCP variation was amplified and tested with allele specific oligonucleotides, as shown in fig 3 , to prove the identity of the SSCP profile apparently characteristic of the E80K mutation. This mutation was identified in $11 / 791(1.4 \%)$ patients and accounted for a third of the patients with an SSCP variation in exon 3 . The remaining 21 SSCP variants have not yet been characterised.

\section{Discussion}

The large increase in the number of papers citing SSCP as their method of mutation

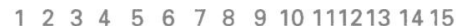

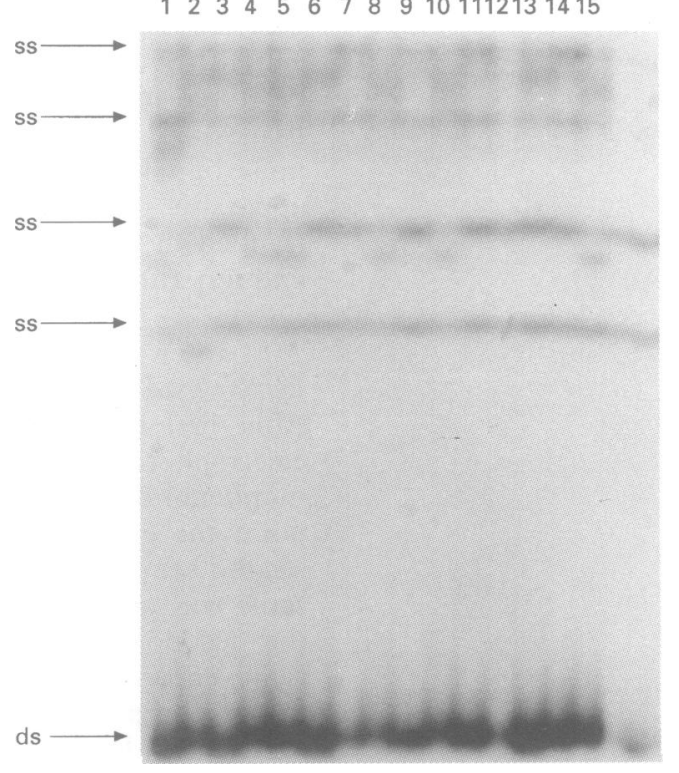

Figure 2 Confirmatory SSCP analysis of PCR products from LDLR gene exon 3 in familial hypercholesterolaemia patients, showing different patterns of variation in exon 3. There are four single strand (ss) bands (presumed to represent multiple conformations), and one double strand (ds) band. In heterozygotes for LDLR gene exon 3 mutations, additional single strand bands are evident. For example, the pattern common to tracks 4, 5, 8, 10, and 15 represents the E80K mutation. 

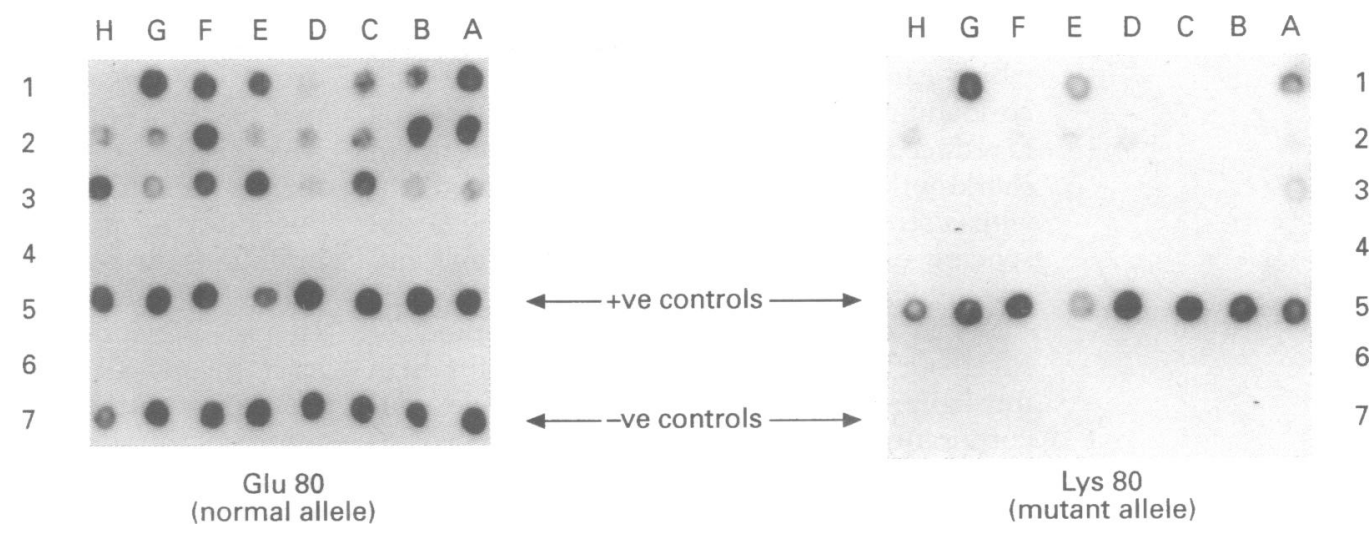

Figure 3 Allele specific oligonucleotide analysis for the E80K mutation in patients with SSCP variations in LDLR gene exon 3. Conditions were as described under methods. PCR products at positions $1 A, 1 E, 1 G, 2 D, 2 E, 2 H$, and $3 A$ contain one normal allele and one E80K allele. Row 5 contains positive controls (with one E80K allele). Row 7 contains negative controls (no E80K allele). Rows 4 and 6 are blank.

screening for putative but unknown mutations in segments of DNA, compared with the number citing techniques such as denaturing gradient gel electrophoresis, ${ }^{20}$ chemical cleavage of mismatch, ${ }^{21}$ and temperature gradient gel electrophoresis, ${ }^{22}$ appears to reflect the relative simplicity of SSCP compared with the other methods in terms of setup or number of steps. Although not sensitive to $100 \%$ of nucleotide variations in a sequence, the high efficiency which appears to be achievable with SSCP $^{15}$ has made it a powerful preliminary method for research studies undertaking de novo characterisation of mutations. However, many SSCP mobility variations are small $(1 \text { to } 5 \%)^{19}$ and long gels (for example, $300 \mathrm{~mm}$ ) may therefore be advisable for maximum sensitivity for mobility shifts, in conjunction with a high quality resolving matrix. We estimate that the smallest mobility change detectable in exon 3 would be about $1 \mathrm{~mm}(0 \cdot 5 \%)$. For large numbers of analyses, for example if the technique were to be used more extensively in the diagnostic setting, labour saving modifications would be essential. We have described here (Methods and table 1), a series of utilities which can increase throughput by an order of magnitude or reduce the time for sample handling, and which have not reduced sensitivity of detection of SSCP variants, as judged from the detection of positive controls.

The use of 96 well microtitre arrays and compatible multichannel devices are well established for cell culture and for analytical reactions. We have recently described a system for simple pattern recognition analysis of known mutations by PCR using horizontal polyacrylamide gels, in which the wells retain the 96 well array (microtitre array diagonal gel electrophoresis, MADGE) ${ }^{23-25}$ (patent application GB9324901.9). The approach described here also uses the $9 \mathrm{~mm}$ pitch of microtitre arrays for high resolution analysis by SSCP. We have stored all of our DNA preparations in master 96 well arrays from which many replicas can be readily made into 96 well plates for PCR. There is no labelling of tubes and the plate is also the storage rack (with identity of sample being related to its position in the array). The storage of many such plates, each containing a small volume of pre-PCR template in fridges or freezers is inconvenient and expensive. To overcome this problem, we allow the DNA templates to dry overnight at room temperature and store all such plates at room temperature. There are the additional advantages that because the template DNA is dry, it has no volume to be taken into account when setting up the PCR reaction and it also reduces the probability of cross contamination when using an automatic multipipette to aliquot the PCR mix. Several wells are left empty of DNA in each array, so that cross contamination can be monitored and so that control samples can be added when necessary. In several months using this procedure we have not found any cross contamination. For samples from which repeated and different PCRs will be undertaken, this enormously reduces necessary staff time and reduces any requirement for laboratory equipment for storage.

"Double gels" and "repeat loading" will each effectively halve the number of gel apparatus, power packs, space, and staff time required to set up analyses of a given number of PCR products. This represents a four-fold improvement in rate of SSCP analysis of PCR products, or four-fold economy in equipment and time. Published approaches for throughput enhancement include pooling of template DNA samples before analysis, ${ }^{26}$ pre-PCR multiplexing of different pairs of PCR primers, ${ }^{27}$ post-PCR ethanol co-precipitation of products before electrophoretic and blot analysis, ${ }^{28}$ and the use of different detection moeities for independent PCR products electrophoresed on the same tracks. ${ }^{29}$ For SSCP, the detection of variant bands in a pool of product from different templates would be difficult and equalisation of competition between templates pooled pre-PCR is problematical. Some multiplexing of PCR primer pairs may, however, be possible. Post-PCR ethanol co-precipitation appears to be worthwhile if many (for example, more than 10) PCR products are being handled, although subsequent differential probing of blots, or different reporter groups is then necessary. Repetitive gel loading has the advantage that co-precipitation is not necessary 
because there is no compromise to the volume which can be loaded, as there would be with co-loading. Staff time for multiple gel loading is reduced eight-fold by the use of custom cut sharktooth combs $(4.5 \mathrm{~mm}$ spacing of teeth) with alternate wells in register with the $9 \mathrm{~mm}$ spacing of multichannel pipette tips and microtitre wells.

We have previously developed a method for silver staining large thin gels, ${ }^{30}$ but for high throughput we prefer radioisotope incorporation in the PCRs, because this obviates the time consuming manual steps. However, we find that a 10-fold dilution of the dCTP concentration in the polymerase mix is possible without compromise to the quality of the autoradiographically detected PCR products, and this enables an equivalent 10 -fold reduction in the amount of radiosotope used. The low quantities of radioisotope used, speed, and simplicity of PCR setup and gel loading (behind shields and glass gel plate) ensure that radioisotope exposure time is minimised. Although this study was undertaken with $20 \mu \mathrm{l}$ PCRs, we have since shown that $10 \mu \mathrm{l}$ PCRs amplify equally well in Hybaid plates, and it may be possible to use $5 \mu \mathrm{l} \mathrm{PCR}$ volumes for economy and safety.

We have not investigated the effect of temperature control on band sharpness. Gels are routinely run at $5 \mathrm{~V} / \mathrm{cm}$ overnight at "room" temperature. This temperature has typically been around $22^{\circ} \mathrm{C}$, with minima and maxima at $20^{\circ} \mathrm{C}$ and $25^{\circ} \mathrm{C}$. At this voltage, power per gel is about $6 \mathrm{~W}$, and gel warming is insignificant. It would be of interest to determine whether precise temperature control might give sharper bands and permit either shorter gels or more repetitive loadings. However, the path length of emission from ${ }^{32} \mathrm{P}$ might then be a limiting factor. Temperature has a clear cut effect on the mobility of some SSCP profiles (unpublished data) but high throughput at predetermined temperatures would require temperature equipment or a temperature controlled room.

From a group of 791 patients with possible, probable, or definite $\mathrm{FH}, 32$ were identified with SSCP variations in exon 3. Our PCR dropout rate was $5 \%$, so we expect that one or two patients with SSCP variations in exon 3 have yet to be identified in this set. Nevertheless, this strategy considerably improves the possibility for molecular genetic studies of $\mathrm{FH}$ mutations in complex populations, many of which represent descriptions of single mutations. ${ }^{4}$ Previous studies have shown that at least $5 \%$ of $\mathrm{FH}$ mutations represent major rearrangements of the LDLR gene, that 1 to $2 \%$ represent the arg $3500 \mathrm{gln}$ mutation in apoB, the protein ligand in LDL for the LDL receptor, ${ }^{31}$ and that 8 to $10 \%$ represent mutations in a "hotspot" region in the 3 ' end of exon 4 of the LDLR gene. ${ }^{11719}$ The latter region encodes repeat 5 of the receptor binding domain, important both for binding apoB in LDL and apoE in IDL. ${ }^{1}$ Many of the exon 4 mutations involve a $\mathrm{CpG}$ site, and such sites are well known to be mutational hotspots on account of their tendency to become methylated to the less chemically stable ${ }^{\mathrm{Me}} \mathrm{CpG}$ form. ${ }^{3233}$ However, there may also be a clinical selection bias if the effect of repeat 5 mutations is more severe than average and there is some evidence that this is the case. ${ }^{17}$ This study has shown that exon 3, which encodes repeat 2 of the LDL binding domain (important for apoB but not for apoE binding), may account for at least a further $4 \%$ of $\mathrm{FH}$ mutations, and also contains a CPG "hotspot" accounting for the glu80lys $(\mathrm{E} 80 \mathrm{~K})$ mutation previously described. ${ }^{10}$ As shown in table 2 , when the repeat domains are aligned, this $\mathrm{CpG}$ site corresponds with the "hot spot" in exon 4. It appears that the presumed evolutionary tandem duplication which has formed the seven repeats of the binding domain has resulted in duplications of a $\mathrm{CpG}$ dinucleotide involved in critical codons (table 2) and that the corresponding $\mathrm{CpG}$ sites in repeats $1,4,6$, and 7 are substituted by TpG. Dependent on which strand deaminates at the ${ }^{\mathrm{Me}} \mathrm{C}, \mathrm{CpG}$ commonly changes to $\mathrm{TpG}$ or $\mathrm{CpA} .^{3233}$ The site in question bridges two codons, so that the $\mathrm{C}$ to $\mathrm{T}$ transition repeats do not change an amino acid in the normal human

Table 2 Multiple nucleotide alignment of the $L D L$ receptor cDNA segments representing the $L D L$ binding domain repeats I-VII. The positions encoding the cysteines conserved in each repeat ${ }^{1}$ are marked. Asterisks mark nucleotides conserved between all repeats. Each $C p G$ site is shown in small case letters. The dinucleotide indicated by exclamation marks bridges conserved codons for the acidic dipeptide sequence Asp-Glu in all seven repeats: in repeats 2, 3, and 5 it is $C p G$, in the remainder it is $T p G$, probably a silent transition from an original ${ }^{M e} C p G$ site. The $C p G$ site in repeat 2 represents the E80K site in exon 3 described here, where E80stop has also been described, the CpG site in repeat 3 is involved in mutations E119stop and E119K ${ }^{4}$ and the site in repeat 5 represents the hotspot in exon 4 where five different mutations (D206E, E207K, E207Q, E207stop, and frameshift 206, 2nt deletion) have been described previously. 117

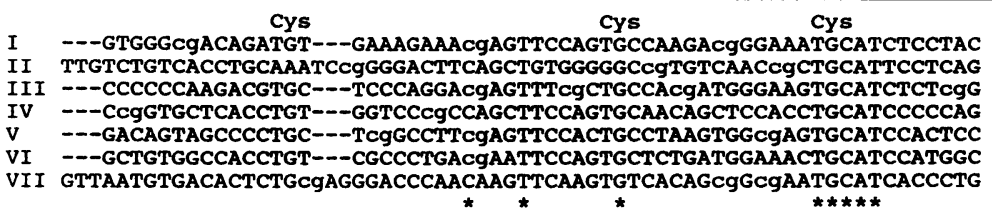

I ---GTGGGCgACAGATGT---GAAAGAAACGAGTTCCAGTGCCAAGACgGGAAATGCATCTCCTAC II TTGTCTGTCACCTGCAAATCCGGGGACTTCAGCTGTGGGGGCCTGTCAACCGCTGCATTCCTCAG III ---CCCCCCAAGACGTGC---TCCCAGGACGAGTTTCgCTGCCACgATGGGAAGTGCATCTCTCgG v ---GACAGTAGCCCCTGC---TCgGCCTTCgAGTTCCACTGCCTAAGTGGCgAGTGCATCCACTCC VII GTTAATGTGACACTCTGCgAGGGACCCAACAAGTTCAAGTGTCACAGCgGCgAATGCATCACCCTG

$\begin{array}{ccc}\text { Cys } & \text { Cys } & \text { AspGlu }\end{array}$ I AAGTGGGTCTGCgATGGCAGCgCTGAGTGCCAGGATGGCTCTGATGAGTCCCAGGAGACgTGC-III CAGTTCgTCTGTGACTCAGACCgGGACTGCTTGGACGGCTCAGACgAGGCC----- TCCTGCIV CTGTGGGCCTGCgACAACgACCCCgACTGCgAAGATGGCTCgGATGAGTGGCCgCAGCgCTGT-V AGCTGGCgCTGTGATGGTGGCCCCgACTGCAAGGACAAATCTGACgAGGAA----AACTGC--VI AGCCgGCAGTGTGACCgGGATATGACTGCAAGGACATGAGCgATGAAGTT------GGCTGC--VII GACAAAGTCTGAACATGGCTAGAGACTGCCgGGACTGTCAGATGAACCATCAAAGAGTGCgGC 
LDLR gene, whereas the $G$ to $A$ transitions change critical glutamates to lysines. Studies of the male germline suggest global methylation in the human LDLR gene (I D Cash, I N M Day, unpublished data). It is likely that there is mutational drive owing to methylation at these CpG sites, and therefore it can be expected that there will be both founder effects (minor or major) because mutations will have occurred early in human evolution (apparently with low negative selection bias ${ }^{34}$ ) and recurrent mutations at the same sites because they are estimated to be 20 -fold more susceptible to mutation than other dinucleotides, ${ }^{32}$ mutating at an estimated rate of $10^{-7}$ per site per gamete. ${ }^{35}$ Construction of simple diagnostic assays for mutations at these sites should therefore prove worthwhile.

At present, we do not have complete data on the sequence changes causing the exon 3 SSCPs or the effects of these changes at the cellular level on plasma lipid levels or clinical phenotype. The main purpose of this paper is to describe a number of modifications of the SSCP method to improve throughput for mutation screening. The availability of the techniques will enable large groups of patients to be screened for such genotype-phenotype studies and also for diagnostic studies.

This work was supported by grants to SEH from the British Heart Foundation (RG5), the John Pinto Foundation, and the Helen Eppel Fund, and to ID, British Heart Foundation the Helen Eppel Fund, and to ID, British Heart Foundation Intermediate

1 Goldstein JL, Brown MS. Familial hypercholesterolemia In: Scriver CR, Beaudet AL, Sly WS, Valle D, eds. The In: Scriver CR, Beaudet Al, Sly WS, Valle D, eds. The metabolic basis of inher

2 Curtis LD, Dickson AC, Ling KL, Betteridge J. Combination treatment with cholestyramine and bezafibrate fo heterozygous familial hypercholesterolaemia. $B M F 1988$; 297:174-5.

3 Kane JP, Malloy MJ, Ports TA, et al. Regression of coronary atherosclerosis during treatment of familial hypercholesterolemia with combined drug regimens. $\mathscr{f} A M A$ 1990;264:3007-12.

4 Hobbs HH, Brown MS, Goldstein JL. Molecular genetics of the LDL receptor gene in familial hypercholesterolemia. Hum Mutat 1992;1:445-66.

5 Koivisto UM, Turtola H, Aalto Setala K, et al. The familial hypercholesterolemia (FH)-North Karelia mutation of the low density lipoprotein receptor gene deletes seven nucleotides of exon 6 and is a common cause of $\mathrm{FH}$ in Finland. $f$ Clin Invest 1992;90:219-28.

6 Leitersdorf E, Tobin EJ, Davignon J, Hobbs HH. Common low-density lipoprotein receptor mutations in the French low-density lipoprotein receptor mutations in the French

7 Leitersdorf E, Van der Westhuyzen DR, Coetzee GA, Hobbs HH. Two common low density lipoprotein receptor gene mutations cause familial hypercholesterolemia in Af rikaners. $₹$ Clin Invest 1989;84:954-61.

8 Horsthemke B, Dunning A, Humphries S. Identification of deletions in the human low density lipoprotein receptor gene. F Med Genet 1987;24:144-7.

9 Sun XM, Webb JC, Gudnason V, et al. Characterization of deletions in the LDL receptor gene in patients with familia hypercholesterolaemia in the United Kingdom. Arterioscle Thromb 1992;12:762-70

10 Webb JC, Sun XM, Patel DD, et al. Characterization of two new point mutations in the low density lipoprotein receptor genes of an English patient with homozygous familial hypercholesterolemia. $\mathcal{f}$ Lipid Res 1992;33:68998.

11 Gudnason V, King Underwood L, Seed M, et al. Identification of recurrent and novel mutations in exon 4 of the LDL receptor gene in patients with familial hypercholesterolaemia in the United Kingdom. Arterioscler Thromb 1993;13:56-63.

12 King Underwood L, Gudnason V, Humphries S, et al. Identification of the 664 proline to leucine mutation in the low density lipoprotein receptor in four unrelated patients with familial hypercholesterolaemia in the UK Clin Genet 1991;40:17-28.

13 Glickman BW, Gorelick NJ, eds. Advanced technology. Mutat Res (special issue) 1993;288:3-181.

14 Orita M, Suzuki Y, Sekiya T, Hayashi K. Rapid and sensitive detection of point mutations and DNA polymorphisms using the polymerase chain reaction. Genomics 1989;5: 874-9.

15 Condie A, Eeles R, Borresen AL, et al. Detection of poin mutations in the p53 gene: comparison of single-strand
conformation polymorphism, constant denaturant gel electrophoresis, and hydroxylamine and osmium tetroxide electrophoresis, and hydroxylamine and

16 Leren TP, Solberg K, Rodningen OK, et al. Evaluation of running conditions for SSCP analysis: application of SSCP for detection of point mutations in the LDL receptor gene. PCR Methods Appl 1993;3:159-62.

17 Gudnason V, Day INM, Humphries SE. Effect on plasma lipid levels of different classes of mutations in the lowdensity lipoprotein receptor gene in patients with familial hypercholesterolaemia. Arterioscl Thromb 1994;14:171722.

18 Miller SA, Dykes DD, Polesky HF. A simple salting out procedure for extracting DNA from human nucleated cells. Nucleic Acids Res 1988;16:1215.

19 Gudnason V, Mak YT, Betteridge J, McCarthy SN, Humphries S. Use of the single-strand conformational polymorphism method to detect recurrent and novel mutations in the low-density lipoprotein receptor gene in patients with familial hypercholesterolaemia: detection of a novel with familial hypercholesterolaemia: detection of a

20 Abrams ES, Murdaugh SE, Lerman LS. Comprehensive detection of single base changes in human genomic DNA using denaturing gradient gel electrophoresis and a GC clamp. Genomics 1990;7:463-75.

21 Saleeba JA, Cotton RG. Chemical cleavage of mismatch to detect mutations. Methods Enzymol 1993;217:286-95.

$22 \mathrm{Ke} \mathrm{SH}$, Wartell RM. Influence of nearest neighbor sequence on the stability of base pair mismatches in long DNA determination by temperature-gradient gel electrophoresis. Nucleic Acids Res 1993;21:5137-43.

23 Day INM, Humphries SE. Electrophoresis for genotyping: microtitre array diagonal gel electrophoresis (MADGE) on horizontal polyacrylamide (H-PAGE) gels, Hydrolink or agarose. Anal Biochem 1994;222:389-95.

24 Day INM, Humphries SE. Electrophoresis for genotyping devices for high throughput using horizontal acrylamide devices for high throughput using horizontal acrylamide gels (H-PAGE) and microtitre array diagonal

25 Day INM, Humphries SE. Microtitre array diagonal gel electrophoresis (MADGE) for population screening of electrophoresis (MADGE) for population screening of
genetic diseases. In: Elles $\mathrm{R}$, ed. Molecular diagnosis of genetic diseases. In: Elles R, ed. Molecular dia
genetic disease. New Jersey: Humana Press, 1995.

26 Gille C, Grade K, Coutelle C. A pooling strategy for heterozygote screening of the delta F508 cystic fibrosis mutation. Hum Genet 1991;86:289-91.

27 Ferrie RM, Schwarz MJ, Robertson NH, et al. Development, multiplexing, and application of ARMS tests for common mutations in the CFTR gene. Am F Hum Genet 1992;51: 251-62.

28 Gyapay G, Morissette J, Vignal A, et al. The 1993-4 Genethon human genetic linkage map. Nature Genet 1994;7: 246-9.

29 Hunkapiller T, Kaiser RJ, Koop BF, Hood L. Large-scale and automated DNA sequence determination. Science 1991;254:59-67.

30 Laywood A, Whittall R, Gudnason V, Humphries S, Day INM. Staining of large $(400 \mathrm{~mm} \times 300 \mathrm{~mm} \times 0.4 \mathrm{~mm})$ gels INM. Staining of large $(400 \mathrm{~mm} \times 300 \mathrm{~mm} \times 0.4 \mathrm{~mm})$
and recovery as dried gels. BioTech $1994 ; 17: 850-2$.

31 Tybjaerg Hansen A, Gallagher J, Vincent J, et al. Familia Tybjaerg Hansen A, Gallagher J, Vincent J, et al. Familial
defective apolipoprotein B-100: detection in the United Kingdom and Scandinavia, and clinical characteristics of ten cases. Atherosclerosis 1990;80:235-42.

32 Cooper DN, Krawczak M. The mutational spectrum of single base-pair substitutions causing human genetic disease: patterns and predictions. Hum Genet 1990;85:55-74

33 Bestor TH, Coxon A. The pros and cons of DNA methylation. Curr Biol 1993;3:384-6.

34 Gudnason V, Day INM. SSCP analysis and DNA sequencing for genetic characterization of a multi-allelic disease, familial hypercholesterolaemia. In: Latchman DS, ed. PCR applications in pathology. Oxford: Oxford University Press, 1995.

35 Bottema CD, Ketterling RP, Vielhaber E, et al. The pattern of spontaneous germ-line mutation: relative rates of mutation at or near CpG dinucleotides in the factor IX gene. Hum Genet 1993;91:496-503. 